\title{
Short Review of Current Research on the Development of Hypoestoxide as a Therapeutic Agent for Parkinson's Disease
}

\section{Emmanuel A Ojo-Amaize* and Howard B Cottam}

Immune Modulation, Inc., P.O. Box 998, Bloomington, CA 92316-0998, USA

*Corresponding author: Emmanuel A Ojo-Amaize, Immune Modulation, Inc., (IMI), P.O. Box 998 Bloomington, CA 92316-0998, USA, Tel. 951-733-6787; E-mail: ojoamaize@aol.com

Received date: May 26, 2016; Accepted date: July 25, 2016; Published date: July 29, 2016

Copyright: (c) 2016 Ojo-Amaize EA, et al. This is an open-access article distributed under the terms of the Creative Commons Attribution License, which permits unrestricted use, distribution, and reproduction in any medium, provided the original author and source are credited.

\begin{abstract}
Parkinson's disease (PD) is a common neurodegenerative disorder belonging to a heterogeneous group of disorders with $\alpha$-synuclein pathology and PD dementia. Hypoestoxide is being developed to combat microgliosis, astrogliosis, loss of dopaminergic neurons, motor behavioral deficits and $\alpha$-synuclein pathology in PD.
\end{abstract}

Keywords: Hypoestoxide; Parkinson's disease; Neuroinflammation; Neurodegeneration; Neuroprotection; $\alpha$-synuclein; NF- $\kappa$ B; PPAR $\gamma$

\section{Introduction}

Hypoestoxide (HE) is a natural diterpene small molecule isolated from the shrub Hypoestes rosea (Acanthaceae), a plant indigenous to the rain forest regions of Nigeria.

HE is a white solid with a molecular weight of $376 \mathrm{~g} / \mathrm{mole}$. The chemical structure of HE was established by NMR and $\mathrm{x}$-ray crystallographic studies and was published in1983 [1]. It contains seven stereo-centers and includes an alpha-beta unsaturated ketone, an acetylated alcohol function, and two epoxide groups (Figure 1).

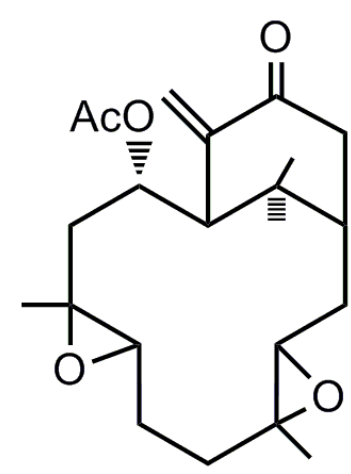

Figure 1: Structure of hypoestoxide (HE).

The structure of HE is such that it is not amenable to synthetic preparation but must be extracted from the natural plant source. Immune Modulation, Inc. has established a robust process for the production of HE under controlled conditions, including the growing, extraction, and purification steps without any deforestation of natural habitats. Studies from our laboratory have demonstrated that HE has anti-inflammatory [2], anti-cancer [3,4], and anti-malarial activity [5], among other beneficial properties.

\section{Intended Target}

HE modulates the activity of NF- $\kappa$ B through I $\kappa B$ kinase inhibition, inhibits Wnt signaling, activates Nrf2 signaling, and activates PPAR $\gamma$. HE penetrates the blood-brain barrier. In fact, the polar surface area for HE is $68.4 \AA 2$ which is considered to be very good for brain penetration. Therefore, we examined the efficacy of HE as an antineuroinflammatory agent for PD using amThyl- $\alpha$-synuclein transgenic mouse model at an exploratory dose of $5 \mathrm{mg} / \mathrm{kg}$, given daily for 30 days. This dose was selected based upon the maximally effective dose that had previously been established in most of the in vivo systems tested to date [2-4].

Results of this study showed that intraperitoneal administration of $\mathrm{HE}$ at $5 \mathrm{mg} / \mathrm{kg}$ ameliorates neuroinflammation, neurodegeneration, and behavioral deficits in this model via modulation of NF- $\kappa$ B activity, thus supporting a role for $\mathrm{HE}$ as an anti-inflammatory drug for the treatment of PD [6]. Importantly, results also showed that HE reduced the neuronal accumulation of $\alpha$-synuclein and thereby reduced the pathology associated with accumulation of $\alpha$-synuclein deposits [6].

A major factor contributing to the neuroprotection that is observed in this preclinical model of PD is thought to be a result of PPAR $\gamma$ activation by HE. It is known that PPAR $\gamma$ agonists exhibit a wide range of activities that positively influence the pathology of $\mathrm{PD}$ in experimental models, and they have the capacity to be neuroprotective by regulating the expression of genes involved in neuronal survival processes [7]. Figure 2 shows a scheme summarizing the neuroprotective mechanisms in which $\operatorname{PPAR} \gamma$ agonists, such as HE, play a significant role in $\mathrm{PD}$ [7].

\section{Rationale for developing hypoestoxide as a therapeutic agent for PD}

$\mathrm{PD}$ is a common incurable neurodegenerative disease that affects about $1 \%$ of the world's population at age 60 [8]. Unfortunately, no treatment with established efficacy in preventing or slowing the progression of neurodegeneration in PD is currently available. HE is a potential disease modifying agent that is predicted to halt or slow the progression of PD by inhibiting or reducing the accumulation of $\alpha$ synuclein protein deposits in brain tissues. 
Citation: Ojo-Amaize EA, Cottam HB (2016) Short Review of Current Research on the Development of Hypoestoxide as a Therapeutic Agent for

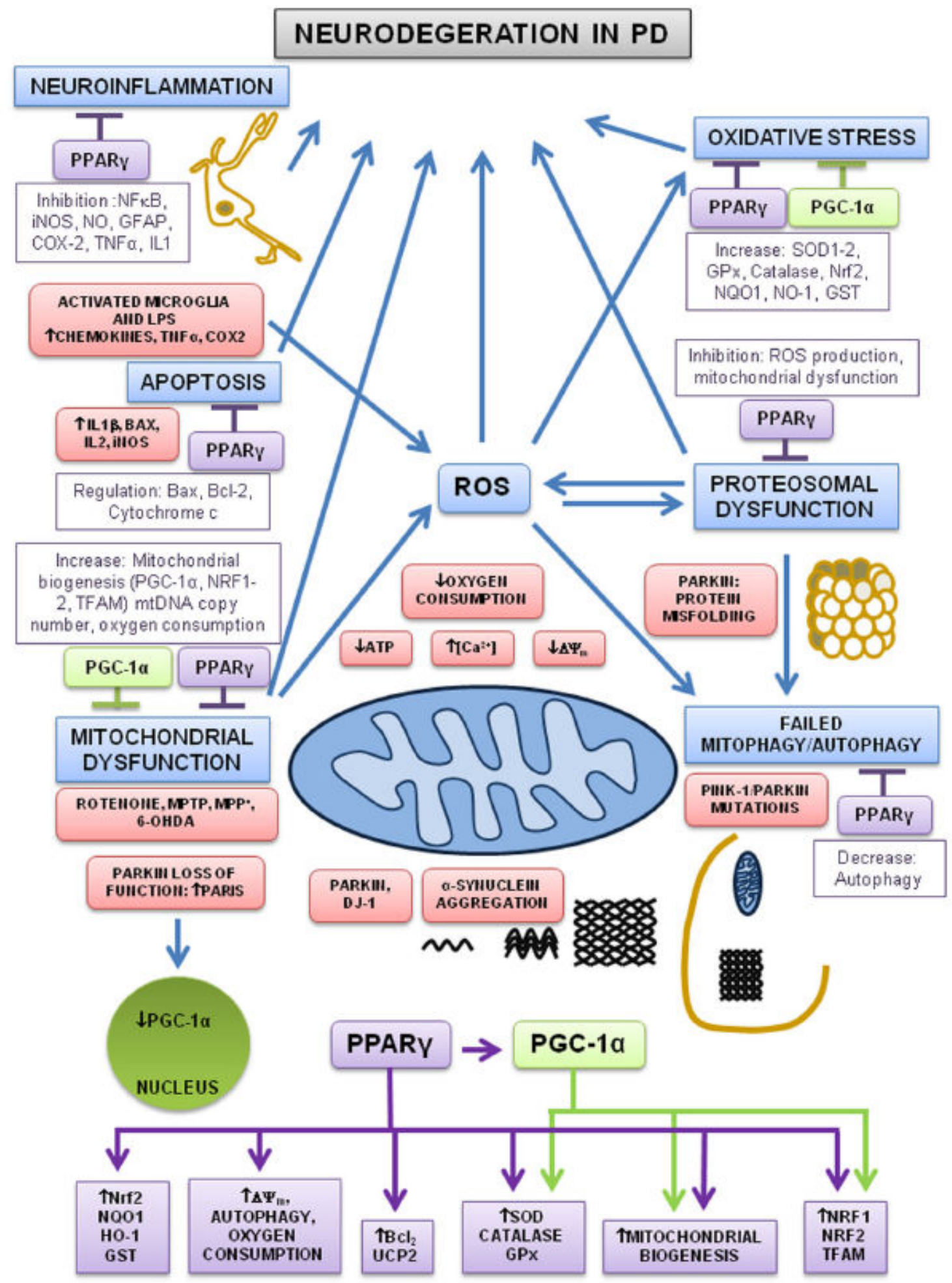

Figure 2: Potential mechanisms of neuroprotection by $\operatorname{PPAR} \gamma$ agonists such as HE in PD. HE activates $\operatorname{PPAR} \gamma$ (purple rectangles) resulting in multiple levels of protection from neurodegeneration (see reference 7).

This disease intervention approach addresses an unmet medical need in the treatment and prevention of PD. Currently approved therapies for PD only address some of the symptoms such as tremors and balance impairment. Once these symptoms are well established in 
Citation: Ojo-Amaize EA, Cottam HB (2016) Short Review of Current Research on the Development of Hypoestoxide as a Therapeutic Agent for

Page 3 of 3

patients, the effectiveness of these therapies is poor and does not address the underlying cause of the symptoms and progression of the disease process. New approaches may change this outcome in the future. A review of many of the drug candidates currently in clinical development is available [9] and describes a wide variety of agents, including adenosine A2a antagonists, new levodopa formulations, antidyskinesia agents, and gene therapies. The goal of some of these experimental therapies is to slow or halt the progression of the disease process, but these will require establishment of proof of concept. In this regard, $\mathrm{HE}$ has been shown to prevent the loss of dopaminergic neurons and ameliorate motor behavioral deficits in a mouse model of PD [6]. These benefits are likely the result of the ability of HE to reduce neuroinflammation and to reduce the accumulation of $\alpha$-synuclein protein deposits. Hypoestoxide inhibits $\alpha$-synuclein aggregation in the Frontal Cortex (neuropil and neurons), Hippocampus and Striatum of the brains of $\alpha$-synuclein transgenic mice (Figure 3) [6].
A

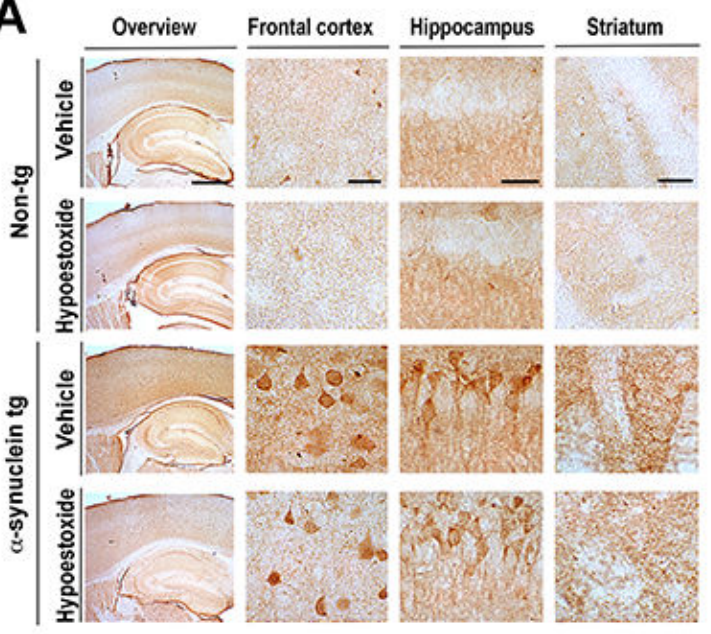

B
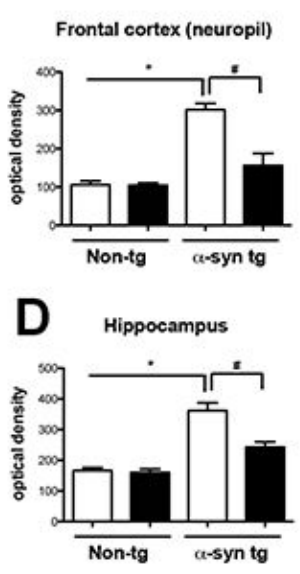

C Frontal cortex (neurons)

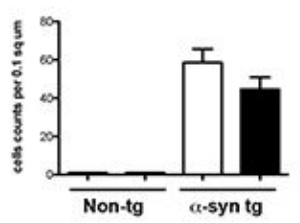

E striatum

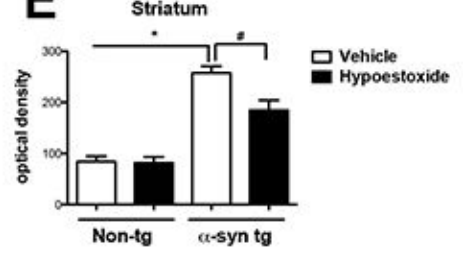

Figure 3: Hypoestoxide-induced inhibition of $\alpha$-synuclein aggregation in the brains of $\alpha$-synuclein transgenic $(\operatorname{tg})$ mice.

Aggregation of $\alpha$-synuclein is a common pathological feature of several neurodegenerative disorders including PD. Transgenic mice overexpressing human $\alpha$-synuclein exhibit impairment in synaptic vesicle exocytosis and a reduction in neurotransmitter release [10].

\section{Conclusion}

HE-induced inhibition of $a$-synuclein aggregation in the brains of $\alpha$-synuclein transgenic mice helps to alleviate the pathological and/or neurological alterations associated with $\alpha$-synuclein aggregation. These features play critical roles in the onset and progression of disease [11]. Thus, an agent such as HE, that is effective at reducing or preventing these features of PD will be effective as a medical intervention to modify the disease process.

\section{References}

1. Adesomoju AA, Okogun JI, Cava MP, Carroll PJ (1983) Hypoestoxide, a new diterpene from Hypoestes rosea (Acanthaceae). Heterocycles 20: 2125-2128.

2. Ojo-Amaize EA, Kapahi P, Vellore NK, Takahashi T, Shalom-Barak T, et al. (2001) Hypoestoxide, a novel anti-inflammatory natural diterpene, inhibits the activity of IkappaB kinase. Cell Immunol 209: 149-157.

3. Ojo-Amaize EA, Cottam HB, Oyemade OA, Okogun JI, Nchekwube EJ (2007) Hypoestoxide inhibits tumor growth in the mouse CT26 colon tumor model. World J Gastroenterol.13: 4586-4588.
4. Ojo-Amaize EA, Nchekwube EJ, Cottam HB, Bai R, Verdier-Pinard, P et al. (2002) Hypoestoxide, a natural non-mutagenic diterpenoid with antiangiogenic and antitumor activity: Possible mechanisms of action. Cancer Research 62: 4007-4014.

5. Ojo-Amaize EA, Nchekwube EJ, Cottam HB, Oyemade OA, Adesomoju AA et al. (2007) Plasmodium berghei: Antiparasitic effects of orally administered hypoestoxide in mice. Exp Parasitol.117: 218-221.

6. Changyoun K, Ojo-Amaize EA, Spencer B, Rockenstein E, Mante M, et al. (2015) Hypoestoxide reduces neuroinflammation and a-synuclein accumulation in a mouse model of Parkinson's disease. J Neuroinflammation 12: 236.

7. Corona JC, Duchen MR (2015) PPAR $\gamma$ and PGC-1 $\alpha$ as therapeutic targets in Parkinson's disease. Neurochem Res 40: 308-316.

8. de Lau LM, Breteler MM (2006) Epidemiology of Parkinson's disease. Lancet 5: 525-535.

9. Hauser RA (2011) Future treatments for Parkinson's disease: Surfing the PD pipeline. Int J Neurosci 121: 53-62.

10. Lashuel H, Overk CR, Oueslati A, Masliah E (2013) The many faces of $\alpha$ synuclein: from structure and toxicity to therapeutic target. Nat Rev Neurosci 14: 38-48.

11. Sanchez-Guajardo V, Tentillier N, Romero-Ramos M (2015) The relation between alpha-synuclein and microglia in Parkinson's disease. Neuroscience 302: 47-58. 